\title{
Effect of droplet impact on molten pool dynamics in hybrid laser-MIG welding of aluminum alloy
}

\author{
Xuyang Chen ${ }^{1,2} \cdot$ Gang $\mathrm{Yu}^{1,2} \cdot$ Xiuli He ${ }^{1,2} \cdot$ Shaoxia $\mathrm{Li}^{1,2} \cdot$ Haibin Miao ${ }^{1,2}$
}

Received: 5 July 2017 / Accepted: 18 December 2017

(C) Springer-Verlag London Ltd., part of Springer Nature 2018

\begin{abstract}
In order to investigate the effect of droplet impact on molten pool dynamics in hybrid laser-MIG (metal inert gas) welding, a three-dimensional mathematical model was developed, and a new approach to simulate the droplet impact was proposed. In the model, the droplet heat and impact under the influence of laser was considered, and the deformation of molten pool was calculated with considering droplet impact and arc pressure. To simplify the model, a modified body heat source model was presented for laser source to take into account multiple reflections and Fresnel absorption. Surface tension, electromagnetic force, and buoyancy were considered to calculate the fluid flow pattern. Furthermore, several dimensionless numbers were used to recognize the importance of the driving forces in molten pool. It was found that molten pool dynamics and final weld bead geometry were strongly affected by the droplet impact. To demonstrate the importance of droplet impact, the temperature, velocity distribution, and the deformation of molten pool were analyzed and compared under different conditions. With considering droplet impact, the penetration was bigger, and the width was smaller. Furthermore, the simulated weld bead geometry was in good agreement with experimental measurement.
\end{abstract}

Keywords Droplet impact $\cdot$ Hybrid laser-MIG welding $\cdot$ Aluminum alloy $\cdot$ Molten pool dynamics $\cdot$ Simulation

\section{Introduction}

Aluminum alloy A7N01 was widely used in high-speed vehicle body due to the substantial specific strength, good crashworthiness, and excellent corrosion resistance. For aluminum alloy, it was difficult to obtain better weld quality because of the high reflectivity and large thermal conductivity, and hybrid laser-MIG welding could overcome these difficulties [1]. During the process of hybrid welding, additional mass, momentum, and energy were brought to the molten pool owing to droplet transition. The surface was seriously deformed, and heat transfer and fluid flow in the molten pool were strongly

Gang Yu

gyu@imech.ac.cn

Xiuli $\mathrm{He}$

xlhe@ imech.ac.cn

1 Key Laboratory of Mechanics in Advanced Manufacturing, Institute of Mechanics, Chinese Academy of Sciences, Beijing 100190, China

2 School of Engineering Science, University of Chinese Academy of Sciences, Beijing 100049, China affected by droplet impact [2]. To a much extent, the weld pool geometry depended on the fluid dynamics. It was necessary to study the molten pool dynamics with considering the effect of droplet impact [3, 4].

So far, there were several mathematical models to investigate the heat transfer and fluid flow in hybrid laser-GMA (gas metal arc) welding. Zhou et al. [5] established a mathematical model to investigate the complicated transport phenomena in spot hybrid laser-MIG keyhole welding. In their model, the continuum formulation was used to handle solid phase, liquid phase, and the mushy zone during the melting and solidification processes. The volume of fluid (VOF) method was employed to handle free surfaces, and the enthalpy method was used for latent heat. They calculated the dynamics of weld pool fluid flow, energy transfer in keyhole plasma, and weld pool. Gao et al. [6] established a mathematical model to simulate the weld pool development and dynamic process in stationary laser-MIG hybrid welding. Droplets impinging, electromagnetic force, and recoil pressure were all considered in their model. Surface tension and buoyancy were considered to calculate the liquid metal flow pattern. They calculated the weld pool shape and liquid metal velocity distribution. Cho et al. [7] established a model to predict molten metal flow in 
$\mathrm{CO}_{2}$ laser-GMA hybrid welding. In their model, an additional conservation equation was newly suggested based on the hypothesis that fluid flow inside a molten pool might affect the alloying element distributions. Meng et al. [8] developed a finite element model to investigate the thermal process of large spot laser + MIG arc brazing-fusion welding. In their model, the laser was treated as a Gaussian plane heat source, the MIG arc was performed as a modified double ellipse Gaussian plane heat source, and the overheated droplet was treated as a uniform body heat source. The calculated weld bead geometry, and the temperature field, especially for the brazed interface agreed well with the experimental results.

Although some achievements had been made by the previous research, there were still some problems existing. All of the abovementioned models showed the complicated phenomena of the hybrid welding process, but they did not focus much on the droplet impact. In these studies, the droplet was assumed to be spherical, and the droplet diameter was assumed to be the same as the diameter of the feeding wire. In fact, there were various droplet transfer modes, and the assumptions were not accurate except for globular transfer mode $[9,10]$. In addition, the droplet forces were modified by laser beam; thereby, the velocity at which the droplet impact the molten pool was altered [11-13]. But in the existing studies, how laser affected the droplet impingement velocity was not considered. What is more, majority of the previous numerical models were related to steel, and aluminum alloy has received less attention.

In this study, a three-dimensional numerical model was developed to simulate the molten pool dynamics with consideration of droplet impact. The molten pool shape and the distributions of temperature and velocity in the weld pool were calculated. A combined model of gauss surface heat source model and cone body heat source model was used to simulate the multiple reflections and Fresnel absorption of the laser energy. The laser-arc interaction was also considered. A new method to calculate droplet impact with considering the influence of laser was proposed. The droplet heat and impact force were considered in analyzing the effects of droplet on the formation of the weld pool. The surface deformation of the weld pool was calculated by considering arc pressure and droplet impact. It was important to detailedly understand the fluid flow phenomena and pattern associated with the weld pool formation for optimization of welding parameters.

\section{Mathematical model}

In this paper, a three-dimensional model was developed to simulate the heat transfer and fluid flow with considering the droplet impact in hybrid laser-MIG welding. The schematic diagram of the laser-MIG welding was shown in Fig. 1. The following assumptions were made to simplify the calculations:

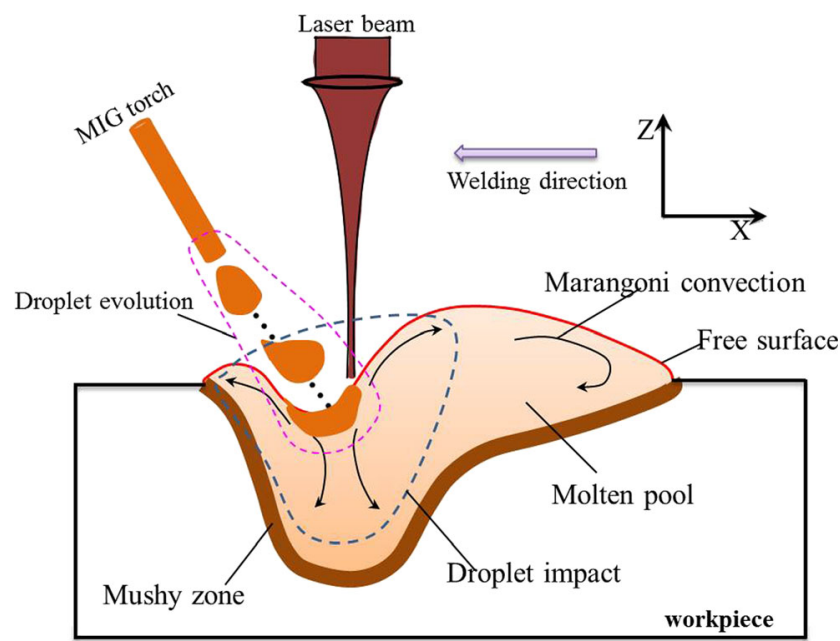

Fig. 1 The schematic sketch of hybrid laser-MIG welding

1. The liquid flow was supposed to be incompressible, Newtonian, and laminar.

2. The thermophysical properties, such as viscosity, thermal conductivity, and specific heat, were taken to be different for the solid and liquid phases, and assumed to be temperature independent.

3. The absorption coefficient of the laser and arc energy by the material was assumed to be constant.

4. The laser energy percentage absorbed by the droplet was ignored.

5. The properties of filler droplet were assumed to be the same as the base metal, and the mass transfer between the droplet and molten pool was neglected.

6. The simulation satisfied the quasi-steady state conditions, and the molten pool under the heat source was fixed.

\subsection{Governing equations}

Based on the abovementioned assumptions, the governing equations, such as the conservation of mass, momentum, and energy equation, are used as follows [14]:

Continuity equation:

$\frac{\partial \rho}{\partial t}+\frac{\partial\left(\rho u_{i}\right)}{\partial x_{i}}=0$

where $\rho$ represents the density of aluminum alloy; $t$ is the time; $x_{i}$ is the distance along the $i=1,2$, and 3 directions; and $u_{j}$ is the velocity component along the $j$ direction.

Momentum equation:

$\frac{\partial\left(\rho u_{j}\right)}{\partial t}+\frac{\partial\left(\rho u_{i} u_{j}\right)}{\partial x_{i}}=\frac{\partial}{\partial x_{i}}\left(\mu \frac{\partial u_{j}}{\partial x_{i}}\right)+S_{u i}$ 
$\mu$ is the effective viscosity, and $S_{u i}$ is the source terms in momentum equation which is expressed as:

$S_{u i}=-\frac{\partial P}{\partial x_{i}}+\frac{\partial}{\partial x_{j}}\left(\mu \frac{\partial u_{j}}{\partial x_{i}}\right)-V \frac{\partial\left(\rho u_{i}\right)}{\partial x}-C\left(\frac{\left(1-f_{l}\right)^{2}}{f_{l}^{3}+B}\right) u_{i}+F$

where $P$ is the pressure, $V$ is the scan speed, the fourth term in the right-hand side in Eq. (3) represents the frictional dissipation of momentum in the mushy zone according to the Carman-Kozeny equation for flow through porous media $[15-17], f_{l}$ is the liquid fraction [18], $B$ is a very small positive constant introduced to avoid division by zero, and $C$ is a constant that takes into account mushy zone morphology. $F$ represents the volume force, which includes the buoyancy force and the electromagnetic force. The buoyancy force can be expressed as:

$F_{b}=\rho g \beta\left(T-T_{a}\right)$

where $\beta$ is the coefficient of volume expansion, $T_{a}$ is the ambient temperature.

The electromagnetic force $F_{L}=J \times B$, where $J$ is the current density vector and $B$ is the magnetic flux vector. The electromagnetic force can be simplified into three-directional $x, y$, and $z$ components [19]:

$F_{L x}=-\frac{\mu_{m} I^{2}}{4 \pi^{2} \sigma_{j}^{2} r} \exp \left(-\frac{r^{2}}{2 \sigma_{j}^{2}}\right)\left[1-\exp \left(-\frac{r^{2}}{2 \sigma_{j}^{2}}\right)\right]\left(1-\frac{z}{H}\right)^{2} \frac{x}{r}$

$F_{L y}=-\frac{\mu_{m} I^{2}}{4 \pi^{2} \sigma_{j}^{2} r} \exp \left(-\frac{r^{2}}{2 \sigma_{j}^{2}}\right)\left[1-\exp \left(-\frac{r^{2}}{2 \sigma_{j}^{2}}\right)\right]\left(1-\frac{z}{H}\right)^{2} \frac{y}{r}$

$F_{L z}=-\frac{\mu_{m} I^{2}}{4 \pi^{2} \sigma_{j}^{2} r} \exp \left(-\frac{r^{2}}{2 \sigma_{j}^{2}}\right)\left[1-\exp \left(-\frac{r^{2}}{2 \sigma_{j}^{2}}\right)\right]\left(1-\frac{z}{H}\right)$

where $\mu_{m}$ is the magnetic permeability, $I$ is the current, $\sigma_{j}$ is the current density distribution parameter, and $H$ is the thickness of workpiece.

Energy equation:

$\frac{\partial(\rho h)}{\partial t}+\frac{\partial\left(\rho u_{i} h\right)}{\partial x_{i}}=\frac{\partial}{\partial x_{i}}\left(\frac{k}{C_{p}} \frac{\partial h}{\partial x_{i}}\right)+S_{h}$

where $h$ is the sensible heat, $k$ is the thermal conductivity, $C_{p}$ is the specific heat, and $S_{h}$ is the source term in energy equation which is expressed as:

$S_{h}=-\frac{\partial(\rho \Delta H)}{\partial t}-\frac{\partial\left(\rho u_{i} \Delta H\right)}{\partial x_{i}}-V \frac{\partial(\rho h)}{\partial x}-V \frac{\partial(\rho \Delta H)}{\partial x}+Q_{\text {laser }}$ where $\Delta H$ is the latent heat [20], and $Q_{\text {laser }}$ is the body heat source of laser.

\subsection{Tracking of free surface}

For hybrid laser-MIG welding, droplets fell into the weld pool and made the surface of the molten pool seriously deformed. The molten pool surface under the droplet impact and arc pressure satisfies the equilibrium condition of the surface in the gravitational field $[21,22]$. The calculations involved minimizing the total energy of the surface. The total energy included the surface energy due to the change in the area of the pool surface, potential energy in the gravitational field, the arc pressure, and the pressure due to impact of the droplet. The control equation for the molten pool deformation is expressed as [23]:

$P_{a}+P_{d}-\rho g \phi+\lambda=-\gamma \frac{\left(1+\phi_{y}^{2}\right) \phi_{x x}-2 \phi_{x} \phi_{y} \phi_{x y}+\left(1+\phi_{x}^{2}\right) \phi_{y y}}{\left(1+\phi_{x}^{2}+\phi_{y}^{2}\right)^{3 / 2}}$

where the variables $\varphi_{x}=\frac{\partial \varphi}{\partial x}, \varphi_{y}=\frac{\partial \varphi}{\partial x}, P_{a}$ and $P_{d}$ represent the arc and droplet impact pressure, respectively. $\gamma$ and $\rho$ are the surface tension and density of the liquid, respectively. The variable $\phi$ is called the configuration function of the weld pool surface that represents the elevation or depression across a datum level.

At the solid boundary: $\varphi(x, y)=0$, and at the symmetry plane: $\frac{\partial \varphi}{\partial y}=0$.

\subsection{Description of the droplet}

In order to simulate the droplet impact on the molten pool, the volume, heat, and impingement of droplet were presented in the equations which described the pool's dynamics. Since the additional volume is equal to that of the feed wire in laserMIG welding $\left(\Delta V_{d}\right)$, the constraining equation is:

$\iint_{S}-\varphi d x d y=\iint_{S} G d x d y=\Delta V_{d}$

where $G$ is the constraining function, and $\Delta V_{d}$ is the volume addition through wire influence in the unit time, which can be expressed as:

$\Delta V_{d}=\frac{\pi}{4} d_{w}^{2} \cdot U_{w}$

where $d_{w}$ is the wire diameter, and $U_{w}$ is the wire feed speed.

The expression for arc pressure may be given as [24, 25]:

$P_{a}=\frac{\mu_{m} I^{2}}{8 \pi \sigma_{j}} \exp \left(-\frac{x^{2}+y^{2}}{2 \sigma_{j}^{2}}\right)$ 
The droplet impact force is related to mass and velocity of the additional filler metal. The volume of the feeding wire in unit time was $\rho_{w} \cdot \frac{\pi}{4} d_{w}^{2} \cdot U_{w}$, and the volume of droplet was $\left(\rho_{w} \cdot \frac{\pi}{4} d_{w}^{2} \cdot U_{w}\right) / f(f$ represented the transfer frequency of the droplet). The volume of droplet was assumed to be the same as the volume of feeding wire in the time of $1 / f$, regardless of the shape. The droplet impact $P_{d}$ can be given as:

$P_{d}(x, y)=\frac{\rho_{w} \cdot \frac{\pi}{4} d_{w}^{2} \cdot U_{w} \cdot V_{d}}{2 \pi \cdot r_{f}^{2} \cdot f} \exp \left(-\frac{r^{2}}{2 r_{f}^{2}}\right)$

where $r_{f}$ is the distribution parameter of droplet impact force [26], $\rho_{w}$ is the density of the wire, and $V_{d}$ is the droplet impact velocity at which droplet impinged the molten pool. Equation (14) was suitable for various modes of droplet transition.

Figure 2 showed the droplet transition in MIG welding and hybrid laser-MIG welding. It was obviously observed that the shape, size, and velocity of the droplet were changed due to the laser beam. According to this, the forces acting on the droplet were affected by the laser beam. Figure 3 showed the sketch of the forces acting on the droplet in MIG welding and hybrid laser-MIG welding. The effect of laser-arc interaction on the droplet was considered. Before impinging onto the base metal, the droplet was driven by gravity $F_{\mathrm{g}}$, electromagnetic force $F_{\text {em }}$, surface tension $F_{\gamma}$, plasma arc drag force $F_{\mathrm{P}}$, and metal vapor reaction force $F_{\mathrm{RL}}$ [27-30]. Under the influence of these forces, the droplet was accelerated and impinged the molten pool at a certain velocity. In hybrid laser-MIG welding, the arc plasma was attracted and compressed due to the plasma induced by the laser, and the forces of the droplet were changed, as shown in Fig. 3. In hybrid laser-MIG welding, the forces of droplet were different from that in pure MIG welding, and the velocity at which the droplet impact the molten pool was modified. The effect of forces was indirectly considered by setting the initial velocity $V_{\mathrm{d}}$ of the droplet.

$Q_{d}$ is the total sensible heat input from the metal droplet. In unit time, the droplet heat $\mathrm{Q}_{\mathrm{d} 0}$ can be given as [31]:

$Q_{d 0}=C_{w} \cdot \rho_{w} \cdot \frac{\pi}{4} d_{w}^{2} \cdot U_{w} \cdot\left(T_{w}-T_{l}\right)$

It was normally approximated by a Gaussian distribution as:

$Q_{d}(x, y)=\frac{C_{w} \cdot \rho_{w} \cdot \frac{\pi}{4} d_{w}^{2} \cdot U_{w} \cdot\left(T_{w}-T_{l}\right)}{2 \pi \cdot r_{f}^{2} \cdot f} \exp \left(-\frac{r^{2}}{2 r_{f}^{2}}\right)$

$C_{w}$ is the specific heat capacity of the wire material, $d_{w}$ is the wire diameter, $T_{w}$ is the droplet temperature, and $T_{l}$ is the liquidus temperature.

\subsection{The heat source model}

In hybrid laser-MIG welding, the base material was irradiated by the high power density of the laser beam, and a keyhole was created due to vapor and recoil pressure. Furthermore, the energy absorption mechanism includes the Fresnel absorption and inverse bremsstrahlung absorption inside the keyhole, which was assumed to be a stable body heat source inside the molten pool [32-35]. Therefore, to describe the laser energy acting on the workpiece, a combined heat source model was applied in this study. The combined laser heat source comprised of a Gauss surface heat source on the top surface and a finite depth Gauss body heat source, as shown in Fig. 4a. In this study, the Gauss surface heat source and finite depth body heat source account for $\chi_{1}$ and $\chi_{2}$ of the laser energy, respectively [36-39]:

$$
\begin{aligned}
& q_{\text {laser }}=\eta\left(\frac{\chi_{1} f_{l} P_{l}}{\pi r_{b}^{2}}\right) \exp \left[-\frac{f\left(\left(x-x_{0}\right)^{2}+y^{2}\right)}{r_{b}^{2}}\right] \\
& Q_{\text {laser }}=\eta \frac{\chi_{2} p_{l}}{\pi R(z)^{2} h}
\end{aligned}
$$

where $\eta$ is the power efficiency; $f_{l}$ is the power distribution factor; $r_{b}$ is the effective beam radius; $h$ is the depth of the body heat source; $P_{l}$ is the laser power; $\chi_{1}$ and $\chi_{2}$ are laser distribution coefficients in the surface and lower part, respectively; and $\chi_{1}+\chi_{2}=1$. The Gauss surface heat source and finite depth body heat source account for 0.3 and 0.7 of the laser energy, respectively [40]. $R(z)$ is the radius of the body heat source at different depths.

Since the arc heat mostly irradiated on the top surface, a Gaussian surface heat source model was used for heat input from the MIG torch, as shown in Fig. 4b:

$q_{\mathrm{arc}}=\eta_{\mathrm{arc}}\left(\frac{f_{\mathrm{arc}} U I}{\pi r_{\mathrm{arc}}^{2}}\right) \exp \left[-\frac{f_{\mathrm{arc}}\left(\left(x-x_{0}-e\right)^{2}+y^{2}\right)}{r_{\mathrm{arc}}^{2}}\right]$

where $U$ is the voltage, $\eta_{\text {arc }}$ is the arc power efficiency, $f_{\text {arc }}$ is the arc heat distribution factor, $e$ is the distance between laser beam and MIG torch and $r_{\text {arc }}$ is the arc heat distribution radius. In hybrid welding, the effective arc radius is smaller than lone MIG welding because the arc becomes constricted due to the laser-arc interaction [39-42].

\subsection{Boundary conditions}

A three-dimensional Cartesian coordinate system is used in the calculation, while only half of the workpiece is considered since the weld is symmetrical about the weld center line. The boundary conditions are further discussed as follows. 
Fig. 2 The droplet transition $\mathbf{a}$ in MIG welding $\mathbf{b}$ in hybrid laserMIG welding
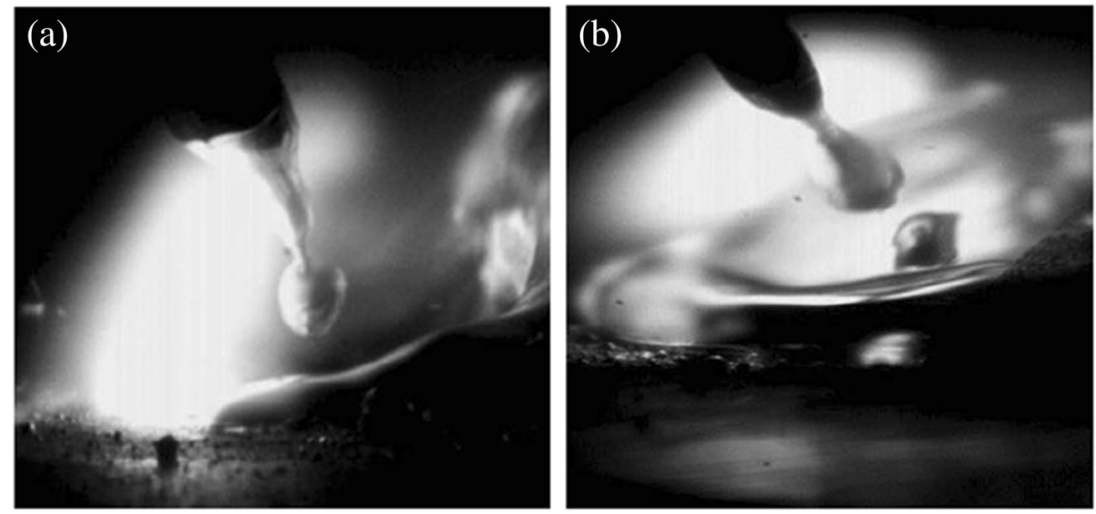

\subsubsection{Top surface}

For energy equation, laser and arc heat input minus convective and radiation heat loss is considered, and the energy boundary condition can be expressed as:

$-k \nabla T \cdot \boldsymbol{n}_{\boldsymbol{b}}=q_{\text {laser }}+q_{\mathrm{arc}}+\mathrm{Q}_{\mathrm{d}}(x, y)-\sigma \varepsilon\left(T^{4}-T_{a}^{4}\right)-h_{c}\left(T-T_{a}\right)$

where $\boldsymbol{n}_{\boldsymbol{b}}$ is the outward normal vector of the top surface. The fourth term in the right-hand side in the equation is the radiation loss, where $\sigma$ is the Stefan-Boltzmann constant, $\varepsilon$ is the surface emissivity, and $h_{c}$ is the heat transfer coefficient.

At the top surface, Marangoni stress arisen from the temperature gradient of surface tension is exerted for momentum equations. The momentum component of the $U$ direction can be given as:

$\mu \frac{\partial u}{\partial z} \cdot \boldsymbol{n}_{\boldsymbol{b}}=f_{l} \frac{\partial \gamma}{\partial T}\left(\frac{d T}{d x} \cdot \boldsymbol{t}_{\boldsymbol{b x}}\right)$

The momentum component of the $V$ direction can be given as:

$\mu \frac{\partial u}{\partial z} \cdot n_{b}=f_{l} \frac{\partial \gamma}{\partial T}\left(\frac{d T}{d y} \cdot t_{b y}\right)$

The momentum component of the $W$ direction can be expressed as:

$w \cdot n_{b}=0$ where $u, v$, and $w$ are the velocity components along the $x, y$, and $z$ directions, respectively, and $\frac{\partial \gamma}{\partial T}$ is the temperature coefficient of surface tension.

$\boldsymbol{t}_{\boldsymbol{b} \boldsymbol{x}}$ is the tangential unit vector parallel to the $\mathrm{x}-\mathrm{z}$ plane.

$\boldsymbol{t}_{\boldsymbol{b} \boldsymbol{y}}$ is the tangential unit vector parallel to the $\mathrm{y}-\mathrm{z}$ plane.

As shown in this equation, the $u$ and $v$ velocities are determined from the Marangoni effect. The $w$ velocity is equal to zero since there is no outward flow at the pool top surface.

\subsubsection{Symmetric surface}

The boundary conditions are defined as zero flux across the symmetric surface as:

$$
\frac{\partial u}{\partial y}=0, \quad v=0, \quad \frac{\partial w}{\partial y}=0 \frac{\partial h}{\partial y}=0
$$

\subsubsection{Other surfaces}

At all other surfaces, temperatures are set at ambient temperature $\left(T_{\mathrm{a}}\right)$ and the velocities are set to be zero:

$$
u=v=w=0, T=298 K
$$

\subsection{Numerical procedures}

The effect of droplet impact on molten dynamics and weld bead geometry in hybrid laser-MIG welding was numerically simulated. The computational domain had dimensions of $32 \mathrm{~mm}$ in length, $10 \mathrm{~mm}$ in width, and $6 \mathrm{~mm}$ in depth, and
Fig. 3 Sketch of the forces acting on the droplet $\mathbf{a}$ in MIG welding and $\mathbf{b}$ in hybrid laser-MIG welding (a)

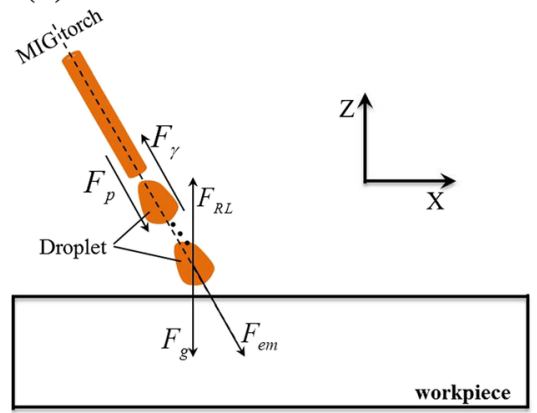

(b)

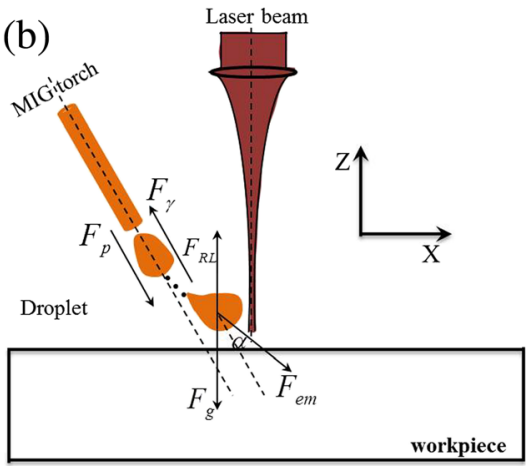


Fig. 4 Schematic representation of heat source models. a Laser heat source model. b Arc heat source model

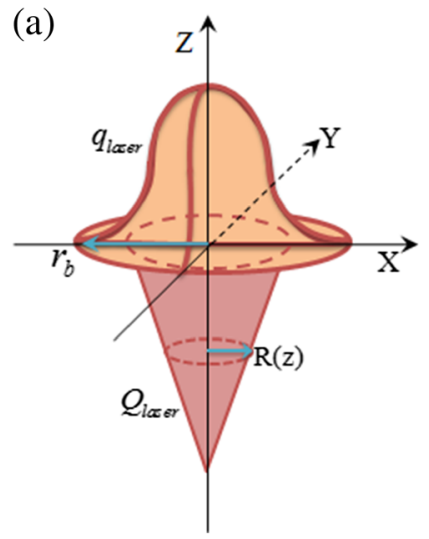

(b)

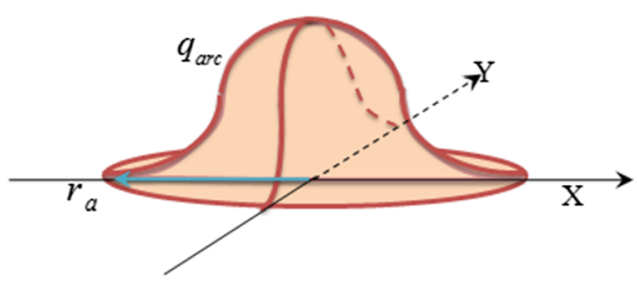

the corresponding grid system used in the present study contained $525 * 135 * 120$ grid points. Half of the workpiece is taken into account for simplification. A finer grid spacing was used near the heat source, and the mesh grids for numerical simulation were shown in Fig. 5.

The SIMPLE algorithm was applied to calculate the program. The time step used in the calculation was $1 \mathrm{~ms}$ to ensure the accurate calculation. The governing equations were solved in each time step, and the surface profile of the molten pool can be obtained based on the temperature field and input parameters. Then the grids were updated to fit the change of geometry, and the governing equations were recomputed in the updated grid system. The calculation procedure was repeated until a converged temperature field and free surface profile were obtained. Table 1 shows the thermophysical properties of A7N01 aluminum alloy. Table 2 shows the calculation data used in this simulation.

\section{Results and discussion}

\subsection{Temperature and velocity fields}

Along the welding direction, the laser beam was behind the MIG torch, and the distance between them was $2 \mathrm{~mm}$. In the given results, the MIG torch located at $X=8 \mathrm{~mm}$, and the laser beam located at $X=10 \mathrm{~mm}$. The initial temperature of the droplet was assumed to be $1000^{\circ}$ higher than the liquidus temperature [45]. The temperature and velocity distributions were calculated with and without considering droplet impact, respectively.

\subsubsection{Simulation results with considering droplet impact}

Figure 6 showed the temperature contour plot and the fluid flow in XZ and XY sections. The configuration of the laser and arc was shown in Fig. 1, and laser was behind the MIG torch along the welding direction. The heat of the arc melted the base metal; then, the molten pool formed. The laser beam directly acted on the liquid metal, which greatly improved the laser energy absorption rate and increased the penetration.
As shown in Fig. 6a, in the center of the arc, the molten pool had a significant concave deformation due to the droplet impact and arc pressure. In the center of the laser, penetration was significantly increased due to the multiple reflections and Fresnel absorption in the keyhole. The surface tension temperature coefficient was negative, which led to an outer flow from the laser center to the periphery. Liquid metal tended to flow downwards, and the outward flow was enhanced due to the hydrostatic pressure. Since the laser beam transferred most of its energy to the keyhole surface, the temperature was higher than the other region and the surface tension was smaller, then the liquid flowed to that region. Due to the comprehensive effect of the droplet impact and the action of downward electromagnetic force, the fluid flow close to the bottom was downward, and a counter-clockwise vortex was formed. Furthermore, the downward liquid flow helped to increase the penetration. During the hybrid welding process, the wire was continuously melted and transferred to the molten pool, and the rear of the molten pool rose due to the additional volume.

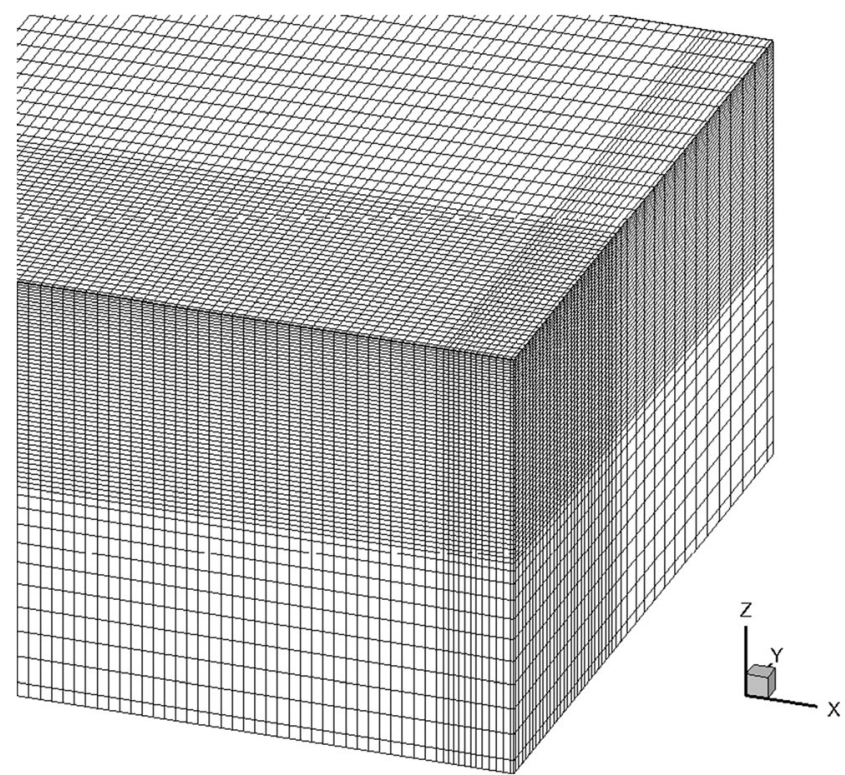

Fig. 5 Mesh grids for numerical simulation 
Table 1 Material properties of A7N01 aluminum alloy [43, 44]

\begin{tabular}{lll}
\hline Symbol & Property (unit) & Value \\
\hline$T_{1}$ & Liquidus temperature $(\mathrm{K})$ & 923 \\
$T_{\mathrm{s}}$ & Solidus temperature $(\mathrm{K})$ & 858 \\
$\rho$ & Density of liquid metal $\left(\mathrm{kg} / \mathrm{m}^{3}\right)$ & 2700 \\
$H_{\text {friz }}$ & Enthalpy of solid a melting point $(\mathrm{J} / \mathrm{kg})$ & $7.6 \times 10^{5}$ \\
$H_{\mathrm{melt}}$ & Enthalpy of liquid a melting point $(\mathrm{J} / \mathrm{kg})$ & $1.1 \times 10^{6}$ \\
$C_{\mathrm{ps}}$ & Specific heat of solid $(\mathrm{J} /(\mathrm{kg} \cdot \mathrm{K}))$ & 881 \\
$C_{\mathrm{pl}}$ & Specific heat of liquid $(\mathrm{J} /(\mathrm{kg} \cdot \mathrm{K}))$ & 1200 \\
$k_{\mathrm{s}}$ & Thermal conductivity of solid $(\mathrm{W} /(\mathrm{m} \cdot \mathrm{K}))$ & 101 \\
$k_{1}$ & Thermal conductivity of liquid $(\mathrm{W} /(\mathrm{m} \cdot \mathrm{K}))$ & 80 \\
$\mu$ & Viscosity of liquid $(\mathrm{kg} /(\mathrm{m} \cdot \mathrm{s}))$ & $1.0 \times 10^{-3}$ \\
$\frac{d \gamma}{d T}$ & Temperature coefficient of surface tension $(\mathrm{N} /(\mathrm{m} \cdot \mathrm{K}))$ & $-1.55 \times 10^{-4}$ \\
$\sigma$ & Stefan-Boltzmann constant $\left(\mathrm{W} /\left(\mathrm{m}^{2} \cdot \mathrm{K}^{4}\right)\right)$ & $5.67 \times 10^{-8}$ \\
$\mu_{\mathrm{m}}$ & Magnetic permeability $(\mathrm{H} / \mathrm{m})$ & $1.26 \times 10^{-6}$ \\
$\varepsilon$ & Surface emissivity & 0.47 \\
\hline
\end{tabular}

Because of the depression and the addition of filler metal droplets, the impact force pushed the surrounding liquid metal upward. The liquid metal accumulated at the rear of the molten pool and gradually solidified; then, the weld reinforcement was formed.

As shown in Fig. 6b, the maximum velocity occurred near the arc center, where the droplet impacted.

The temperature and velocity profiles showed that the highest temperature in the molten pool was $2897 \mathrm{~K}$, and the maximum velocity was $1.3 \mathrm{~m} / \mathrm{s}$. Velocity near the arc center was obviously increased on the top surface due to droplet impact. For aluminum alloy, the temperature coefficient of surface tension was negative, and the fluid flowed outward, from a location at higher temperature to a location at lower temperature. Since the temperature of the droplet was $1000^{\circ}$ higher than the melting point [45], a heat transfer occurred

Table 2 Process parameters

\begin{tabular}{lll}
\hline Symbol & Parameter (unit) & Value \\
\hline$P$ & Laser power (W) & 1000 \\
$r_{\mathrm{b}}$ & Laser radius (mm) & 0.15 \\
$I$ & Welding current (A) & 150 \\
$U$ & Voltage (V) & 21.3 \\
$V$ & Scanning speed (mm/s) & 12 \\
$d_{\mathrm{w}}$ & Wire diameter(mm) & 1.2 \\
$U_{\mathrm{w}}$ & Wire feed speed (m/min) & 9.3 \\
$T_{\mathrm{w}}$ & Droplet temperature (K) & 1923 \\
$\sigma_{\mathrm{j}}$ & Arc current flux distribution parameter (mm) & 3.0 \\
$r_{\mathrm{f}}$ & Distribution parameter of droplet (mm) & 1.0 \\
$f$ & Frequency of droplet transition (Hz) & 317 \\
$T_{\mathrm{a}}$ & Ambient temperature (K) & 298 \\
$e$ & Distance between laser and MIG torch (mm) & 2 \\
\hline
\end{tabular}

between the droplet and the molten pool when the droplet impinged the molten pool. The temperature in the arc center was much higher than the liquidus temperature. At the top surface, the shape of the pool was ellipse, and the liquid flowed outward from the center to the periphery.

The temperature and velocity distributions of $\mathrm{YZ}$ sections at the different locations of the molten pool were shown in Fig. 7. Figure $7 \mathrm{a}$ was the temperature and velocity distributions in the arc center. The molten pool had a large concave deformation, and the temperature in the arc center was higher than the liquidus temperature because of the droplet's heat. The droplet impingement could easily bring in thermal energy to the bottom of the molten pool. Figure $7 \mathrm{c}$ was the temperature and velocity distribution in the laser action center; there was a deep penetration and a high temperature and velocity because of the multiple reflections and Fresnel absorption in the keyhole. Due to the high power density of the laser, the maximum of temperature occurred in the laser center. Figure $7 \mathrm{~b}$ was the temperature and velocity distributions between the laser center and arc center. Due to the influence of the droplet and laser, the deformation was obvious and the temperature was relatively high at this position. Figure $7 \mathrm{~d}$ was the temperature distribution of the highest position of the molten pool. Due to the droplet impact and additional volume, the liquid metal gathered at the rear of the molten pool; then, the liquid level rose.

From the temperature and velocity profiles in Fig. 7 , the droplet impact made the liquid flow bring the thermal energy to the bottom more easier, which contributed to increase the penetration. As soon as the droplet impacted the molten pool, liquid flowed outward and the droplet become flatter. The droplet brought the additional mass, momentum, and energy into the molten pool, which greatly affect the temperature distribution, fluid flow, and the shape of the molten pool. 
(a)

$T(K): 400 \quad 600 \quad 800 \quad 858100012001400160018002000220024002600$

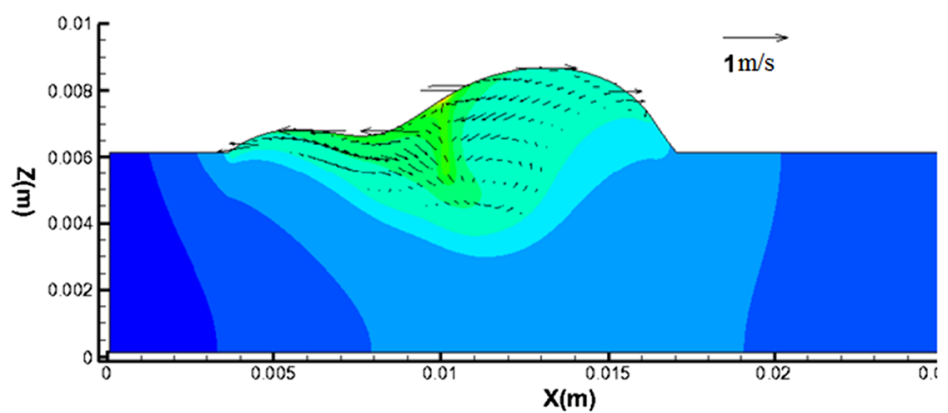

(b)

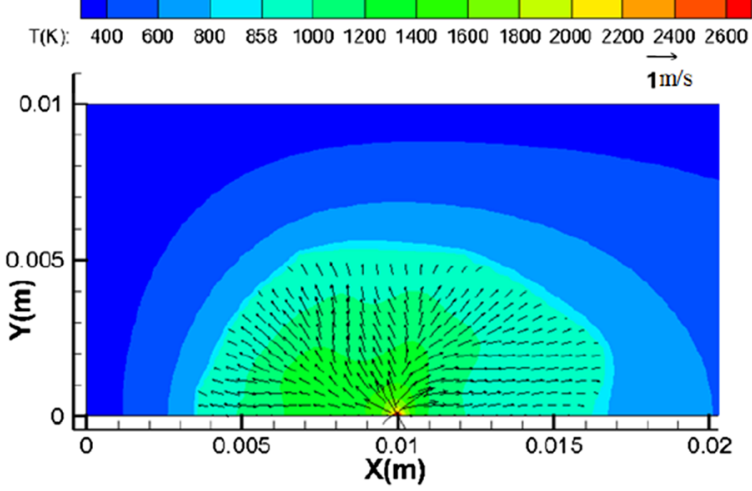

Fig. 6 The temperature and velocity distribution in different sections. a XZ section. b XY section

\subsubsection{Simulation results without considering droplet impact}

In order to demonstrate the effect of the droplet impact on the molten pool dynamics, the temperature distribution, velocity distribution, and deformation without considering the droplet impact were calculated, as shown in Fig. 8. From the temperature and velocity profiles, the maximum temperature was $2799 \mathrm{~K}$, and the maximum velocity was $1.2 \mathrm{~m} / \mathrm{s}$. The maximum velocity was at the location where the temperature was the highest. In other words, the maximum velocity was presented at the location of the laser center. Due to no droplet

(a)

$\mathrm{T}(\mathbf{K}) 400 \quad 600 \quad 800 \quad 85810001200160018002000220024002600$

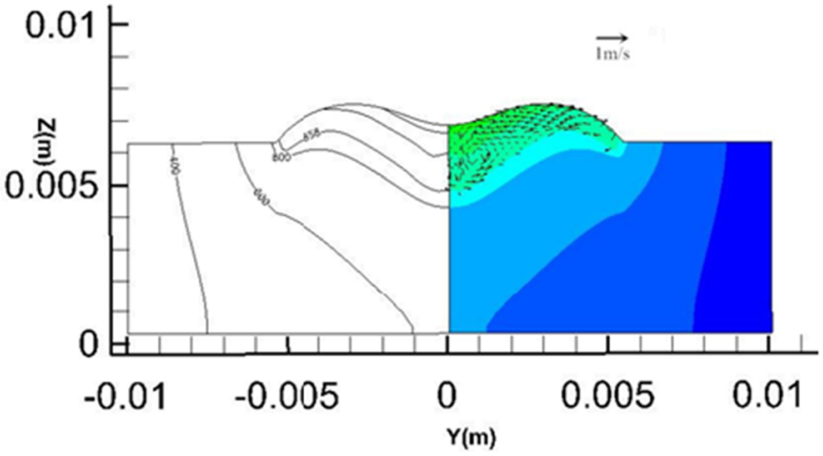

(b)

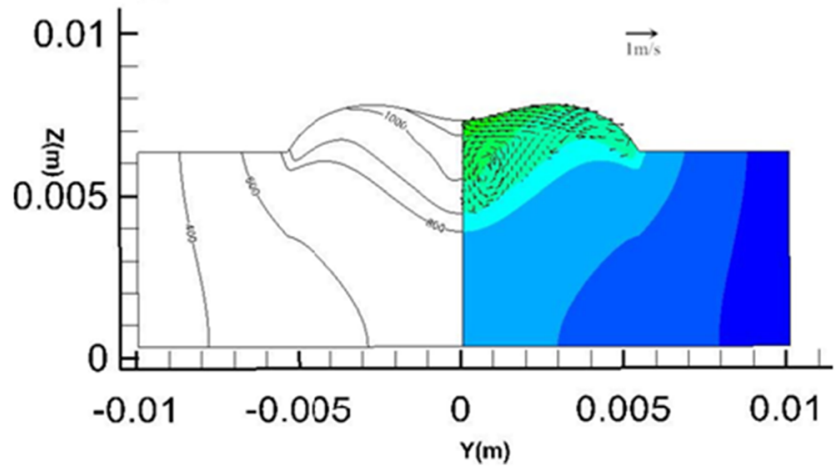

impact, there was no concave deformation, and there was not enough force to push the liquid upward. Therefore, velocity near the arc center did not obviously increase on the top surface. The average velocity was about $0.4 \mathrm{~m} / \mathrm{s}$ smaller than that with considering droplet impact, and there was no big enough force to push the surrounding liquid upward.

Figure 9 showed the temperature and velocity distributions of the YZ section at different locations in the pool, without considering the droplet impact. Figure 9a was the temperature and velocity distributions in the arc center, and there was no concave deformation in this position. Figure $9 \mathrm{c}$ was the

(c)

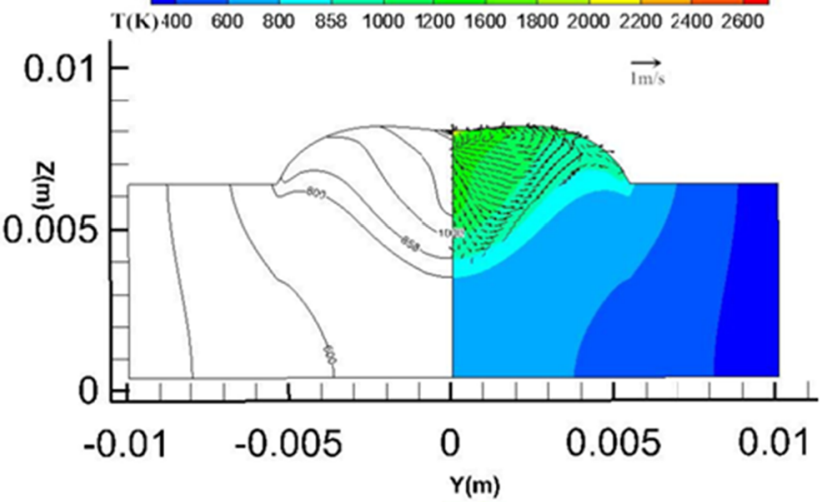

(d)

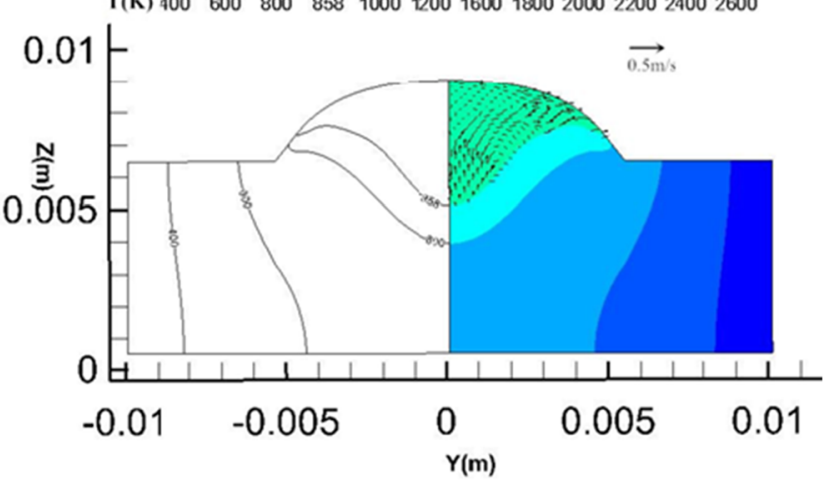

Fig. 7 The temperature and velocity distributions of the YZ section. a $X=8 \mathrm{~mm}$. b $X=9 \mathrm{~mm}$. c $X=10 \mathrm{~mm}$. d $X=13 \mathrm{~mm}$ 
(a)

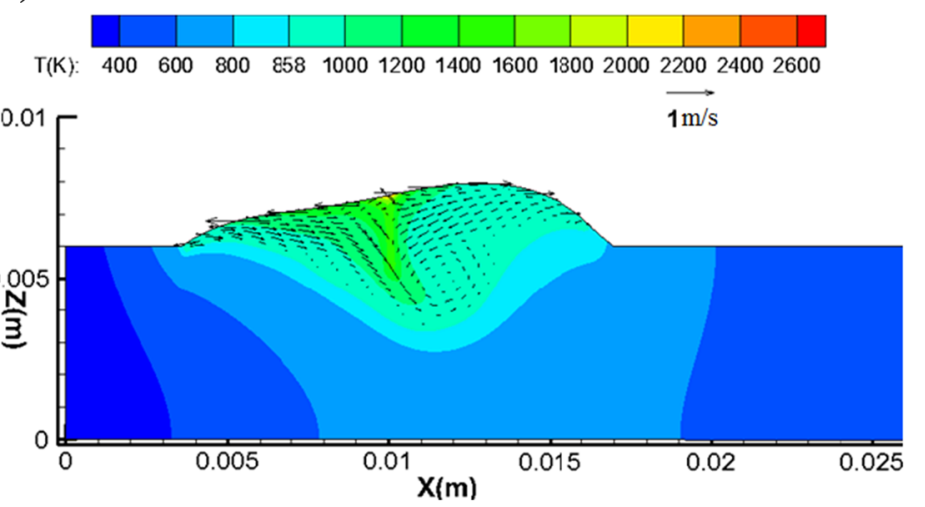

(b)

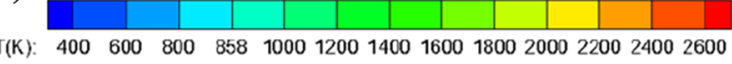

$\overrightarrow{1 \mathrm{~m} / \mathrm{s}}$

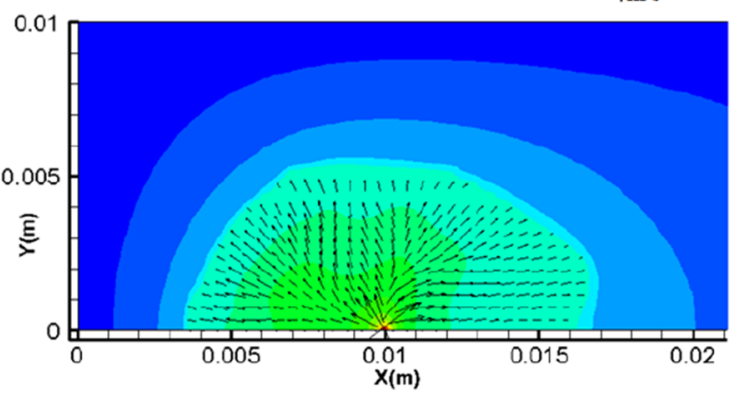

Fig. 8 The temperature and velocity distribution of different sections. a XZ section. b XY section

temperature and velocity distributions in the laser center. Figure $9 \mathrm{~b}$ was the temperature and velocity distributions between the laser center and arc center. Because of no droplet impact, there was no obvious deformation either. Figure 9d was the temperature and velocity distributions of the highest position of the molten pool. Because of the addition of filler metal droplet, the pool surface behind the arc rose and the weld reinforcement was formed.

(a)

T(K) $400 \quad 600800858100012001400160018002000220024002600$

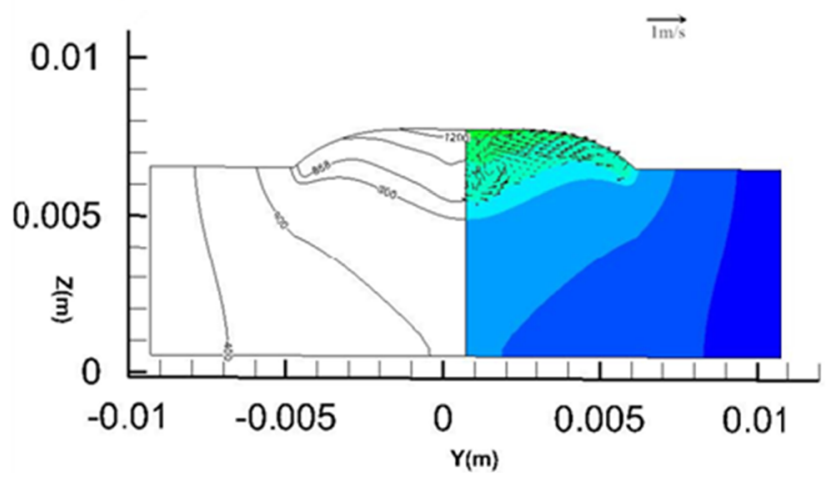

(c)
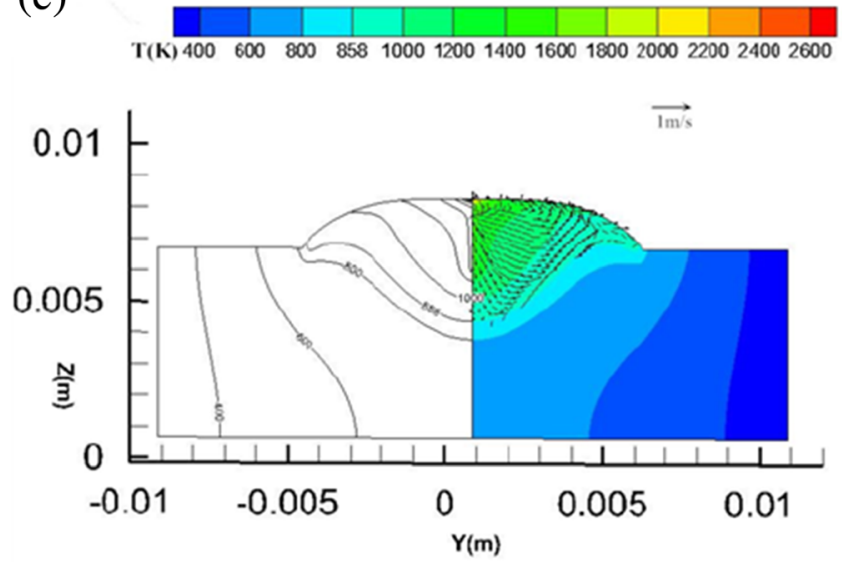

\subsection{Effect of droplet impact}

In order to analyze the effect of droplet impact on molten pool dynamics, the relative calculation results were compared in different sections. Figure 10 showed the influence of droplet impact on the molten shape. The solid lines represented the calculated fusion line for considering arc heat, droplet heat, and its impact. The dashed lines were used for considering

(b)
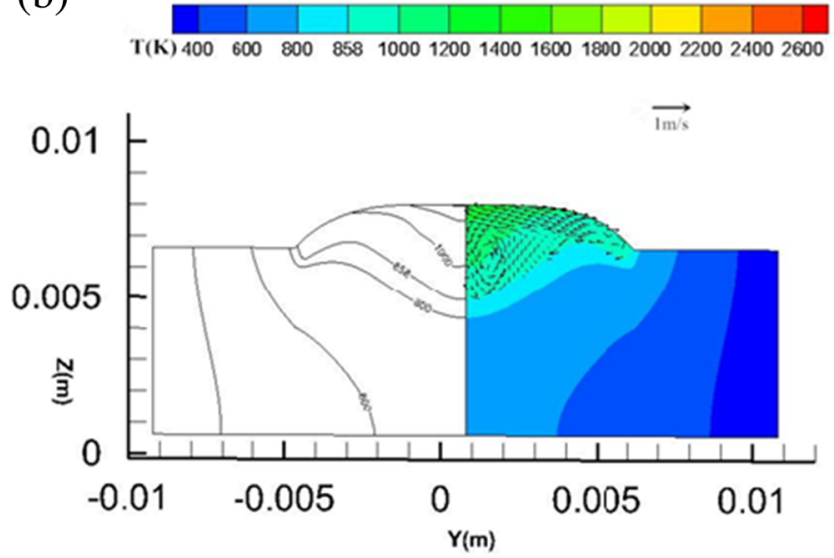

(d)
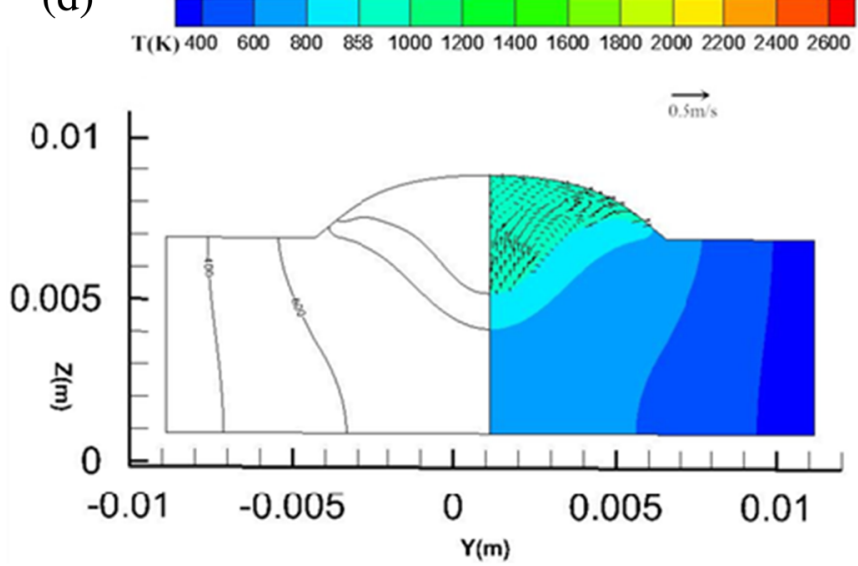

Fig. 9 The temperature and velocity distribution of the YZ section. a $X=8 \mathrm{~mm}$. b $X=9 \mathrm{~mm}$. c $X=10 \mathrm{~mm}$. d $X=13 \mathrm{~mm}$ 


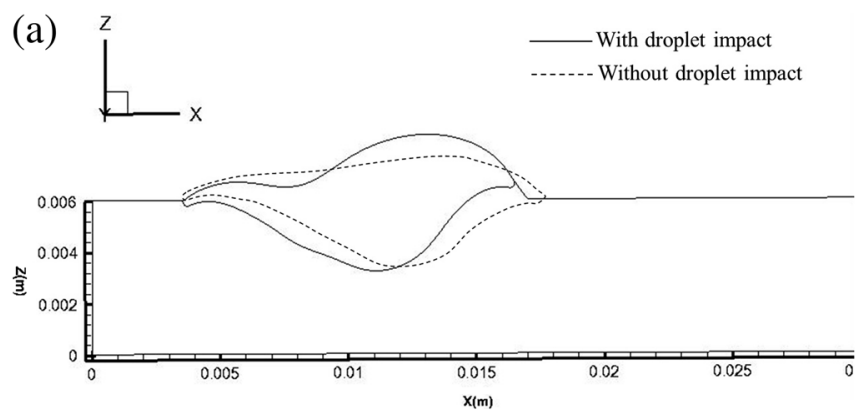

(b)

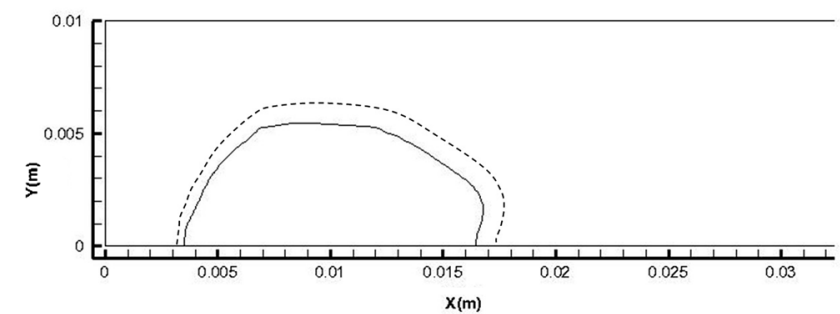

(c)

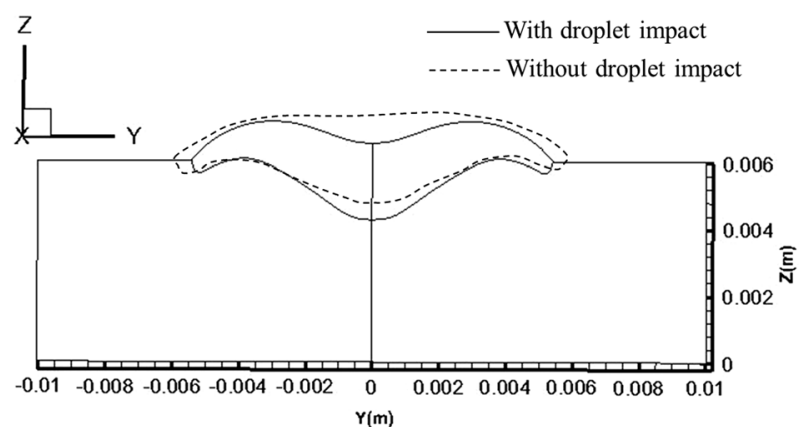

(d)

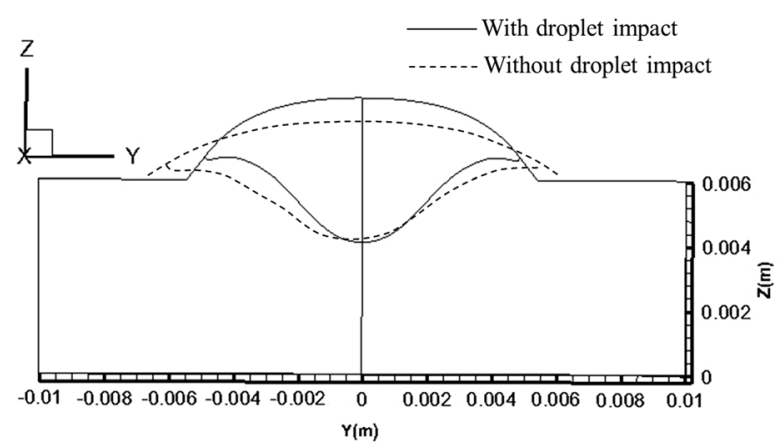

Fig. 10 Comparison of the molten pool shape for two cases, with and without considering droplet impact. a XZ cross section. $\mathbf{b} \mathrm{XY}$ cross section. $\mathbf{c} \mathrm{YZ}$ cross section. $(X=8 \mathrm{~mm})$. d YZ cross section $(X=13 \mathrm{~mm})$

both arc heat and droplet heat, not considering its impact. Figure 10a was a view showing the shape of the XZ section. With considering droplet impact, the penetration in the arc center was bigger than that without droplet impact. Meanwhile, the length of the molten pool was smaller than that without considering droplet impact, and the height of the weld seam was relatively bigger. Figure $10 \mathrm{~b}$ was the comparison of top surfaces. With considering droplet impact, the liquid flowed downward and made the surface depressed, while the liquid tended to be flat at the top surface without considering droplet impact. Therefore, without considering droplet impact, both the length and width of the molten pool were bigger than that with considering droplet impact. Figure 10c showed the shape of the molten pool in the $\mathrm{YZ}$ section of the arc center. From the comparison, the surface

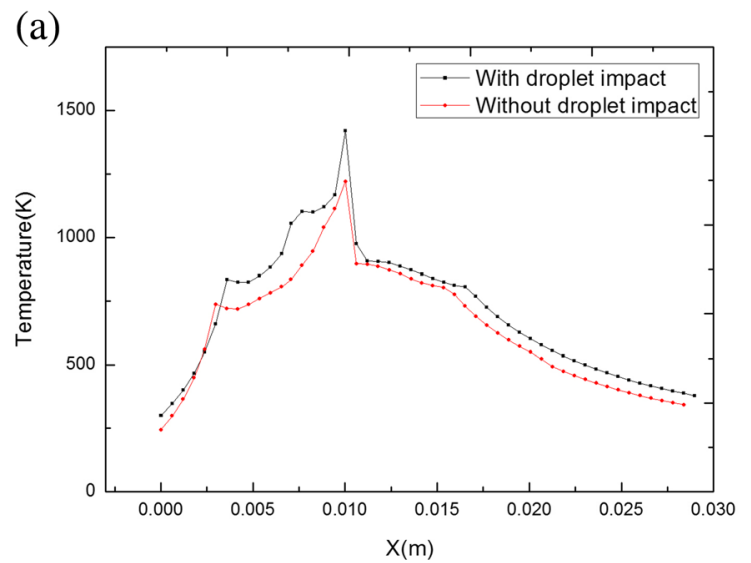

depression of the molten pool was severe because of droplet impact. The arc center had a significant concave deformation with considering droplet impact, and the penetration was larger than that without droplet impact. From Fig. 10d, with considering droplet impact, the impingement force pushed the surrounding liquid upward, and the height of the weld reinforcement was bigger than that without considering droplet impact.

In order to deeply investigate the effect of droplet impact on molten pool dynamics, the data at a certain location $(z=$ $6 \mathrm{~mm}$ in the $\mathrm{XZ}$ section) was extracted and the comparison analysis were carried out.

Figure 11 compared the temperature and velocity profiles with and without droplet impact. From Fig. 11a, the highest temperature appeared in the laser center, and the temperature

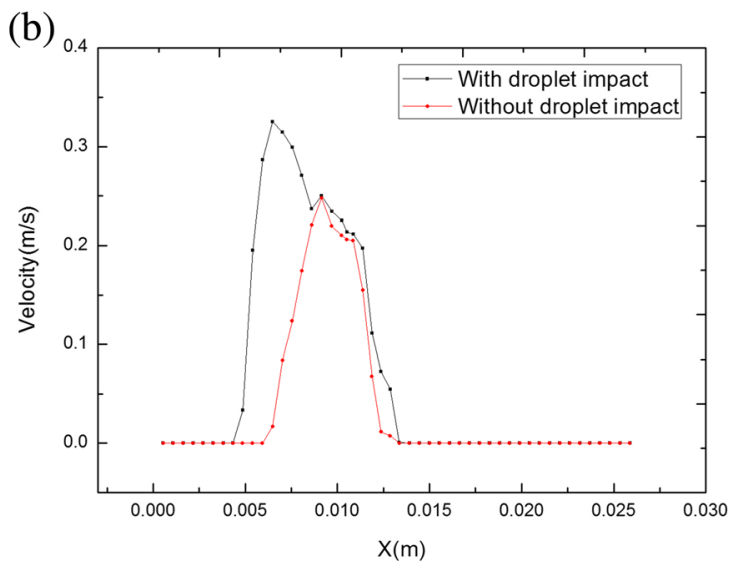

Fig. 11 The temperature and velocity evolution at different locations ( $z=6 \mathrm{~mm}$ in the XZ section). a Temperature evolution. b Velocity evolution 
Table 3 The dimensionless numbers in different conditions

\begin{tabular}{lll}
\hline Dimensionless number & With droplet impact & Without droplet impact \\
\hline $\mathrm{Gr}$ & 1536.36 & 2439.69 \\
$\mathrm{Ma}$ & $14.45 \times 10^{5}$ & $16.86 \times 10^{5}$ \\
$\mathrm{Re}_{\mathrm{m}}$ & $1.94 \times 10^{6}$ & $1.94 \times 10^{6}$ \\
$\mathrm{Re}_{\mathrm{s} / \mathrm{b}}$ & 940.62 & 691.07 \\
$\mathrm{Re}_{\mathrm{s} / \mathrm{m}}$ & 0.745 & 0.869 \\
$p e$ & 54.675 & 35.44 \\
\hline
\end{tabular}

difference is obvious surrounding the arc center. Under the droplet impact, the thermal energy was brought to the bottom of the molten pool more easier. With considering droplet impact, the maximum temperature was about $300^{\circ}$ higher than that without considering droplets. From Fig. 11b, the maximum speed appeared near the arc center with considering droplet impact. Meanwhile, the maximum speed appeared at the location of the laser without considering droplet impact. With considering droplet impact, the maximum speed was about $0.15 \mathrm{~m} / \mathrm{s}$ higher than that without considering droplets.

\subsection{Analysis of driving forces}

In order to evaluate the relative importance of different driving forces in the molten pool, several dimensionless numbers were used in the study. The driving forces for fluid flow in the weld pool, considered in this study, include the surface tension, electromagnetic force, and buoyancy. Grashof number determines the ratio of buoyancy force to viscous force and is calculated by:

$G r=\frac{\text { buoyancy force }}{\text { viscous force }}=\frac{g \beta L^{3} \Delta T \rho^{2}}{\mu^{2}}$

where $g$ is the gravitational acceleration, $\beta$ is the thermal expansion coefficient, $\Delta T$ is the temperature difference between the maximum temperature in the molten pool and the solidus temperature, and $L$ is a characteristic length, which is approximated by one eighth of the pool radius [18].

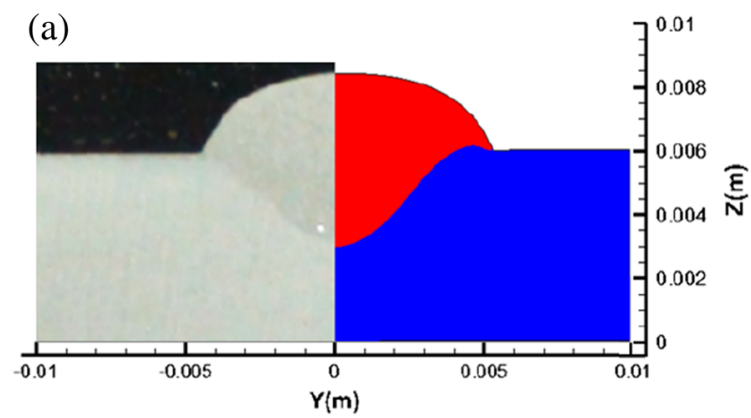

Surface tension Reynolds number described the ratio of surface tension (Marangoni) force to viscous force and is given as:

$M a=\frac{\text { surface tension }}{\text { viscous force }}=\frac{\rho L \Delta T \mid \partial \gamma / \partial T}{\mu^{2}}$

Electromagnetic Reynolds number defines the ratio of electromagnetic (Lorentz) force to viscous force and is given as:

$\operatorname{Re}_{m}=\frac{\text { Electromagnetic force }}{\text { viscous force }}=\frac{\rho \mu_{m} I^{2}}{4 \pi^{2} \mu^{2}}$

The relative significance of these driving forces can be judged using the combination of these dimensionless numbers. The ratio of Marangoni force to buoyancy force is determined by:

$\operatorname{Re}_{s / b}=\frac{M a}{G r}=\frac{\text { surface tension }}{\text { buoyancy }}=\frac{\Delta T|\partial \gamma / \partial T|}{g \beta L^{2} \Delta T \rho}$

And the ratio of surface tension to electromagnetic force is determined by:

$$
\begin{aligned}
\operatorname{Re}_{s / m} & =\frac{M a}{\operatorname{Re}_{m}}=\frac{\text { surface tension }}{\text { electromagnitic force }} \\
& =\frac{4 \pi^{2} L \Delta T|\partial \gamma / \partial T|}{\mu_{m} I^{2}}
\end{aligned}
$$

The effects of heat transfer by convection and conduction on the molten pool can be estimated by the dimensionless Peclet number, which is evaluated by:

$P e=\frac{\text { convective heat transfer rate }}{\text { conductive heat transfer rate }}=\frac{U_{\max } \rho C_{p} L}{k}$

where $U_{\max }$ is the maximum velocity in the molten pool.

Based on the equations explained above, the calculated results were summarized in Table 3.

(b)

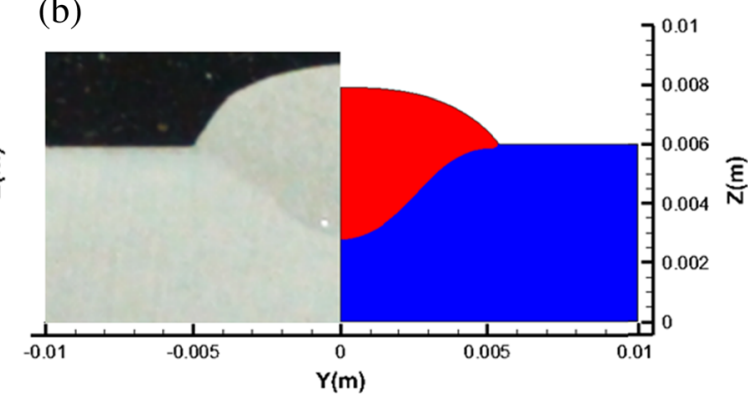

Fig. 12 Comparison of cross-section between calculated and experimental results, $\mathbf{a}$ with droplet impact and $\mathbf{b}$ without droplet impact 
(a)

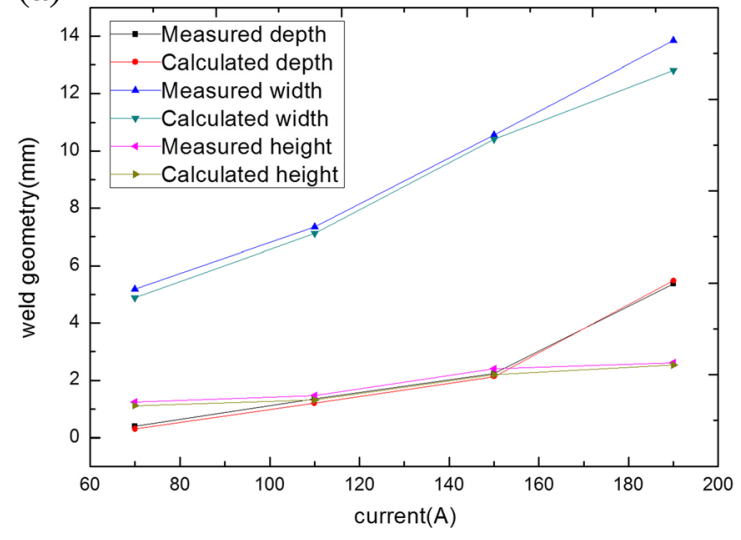

(b)

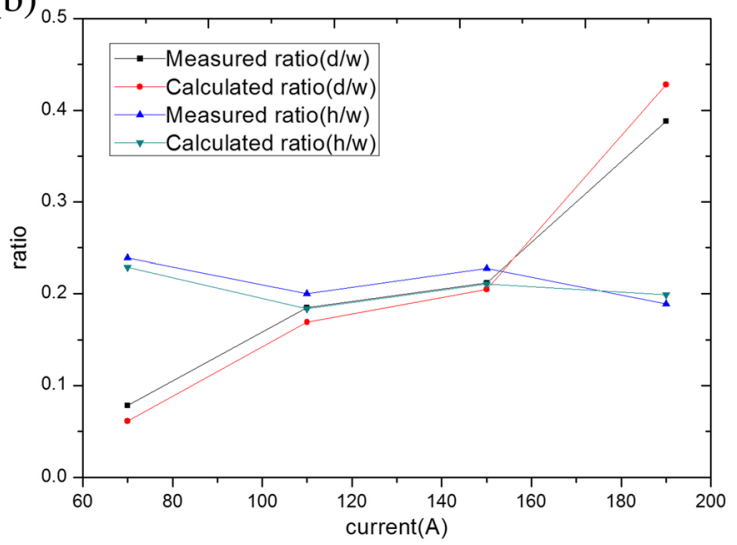

Fig. 13 The comparison of weld geometry and ratio between calculated and experimental results. a Weld geometry. b Ratio

Table 3 compared the dimensionless numbers with and without droplet impact. From Table 3, the dimensionless numbers were different except for $\mathrm{Re}_{\mathrm{m}}$. The Gr showed that buoyancy was much greater than viscous force, and the value was higher without droplet impact. The Ma showed that surface tension was much greater than viscous force, and the value was also higher without droplet impact. The $\mathrm{Re}_{\mathrm{s} / \mathrm{b}}$ showed that surface tension was much greater than buoyancy, and the value was lower without droplet impact. The $\mathrm{Re}_{\mathrm{s} / \mathrm{m}}$ showed that surface tension and electromagnetic force were of the same order, and the electromagnetic force was greater than surface tension. In addition, the value of $\mathrm{Re}_{\mathrm{s} / \mathrm{m}}$ was higher without droplet impact. The Peclet number is much greater than 1, which meant that convection played a significant role in the heat transfer process. With considering droplet impact, the characteristic velocity of the molten pool increased, and the flow was relatively strong, which can result in a more homogenous molten pool.

From Table 3, for both conditions, fluid flow was mostly driven by the electromagnetic force and surface tension, and to a much lesser extent, by the buoyancy force. The molten pool shape and weld quality depended on the heat transfer and fluid flow, and the effect of droplet impact could not be ignored.

\subsection{Experiments and model validation}

In order to validate the model, some experiments were carried out by using a Nd:YAG laser accompanied by a MIG torch. Comparison between simulated and experimental transverse weld pool cross-sections were shown in Fig. 12.

In Fig. 12a, arc heat, droplet heat, and impact were considered, and the calculated results were consistent with the experimental results. In Fig. 12b, both arc heat and droplet heat were considered, but the droplet impact was not considered. The calculated weld height was about $1 \mathrm{~mm}$ smaller than the experimental result. From Fig. 12, with considering droplet impact, the shape of the cross section was in better agreement with the experiment.

Keeping the laser power constant, the depth, width, and the ratio of the weld seam in different currents were calculated. Compared with the experimental results, the curves were shown in Fig. 13. In Fig. 13a, the measured and calculated depth, width, and height of the weld seam were compared. In Fig. 13b, the ratio of depth and width together with the ratio of height and width were calculated to compare the calculated and experimental results. From Fig. 13, for different currents, the calculated results were consistent with the experimental results, showing the validity of the numerical model presented in this paper. The additional mass, momentum, and energy was brought to the molten pool by the droplet, and the droplet impact strongly affected the weld shape and geometry. The simulation of the droplet impact and molten pool dynamics provided a foundation for the processing experiment in the future.

\section{Conclusions}

The major aim of this work was to investigate how droplet impact affects the molten pool dynamics, shape, and dimensions in hybrid laser-MIG welding of aluminum alloy plates. Several experiments were performed to validate the numerical model, and the simulation results were in good agreement with experiments. Some of the important findings from the investigation were as follows:

1. Simulation results were presented to illustrate the importance of droplet impact on molten pool dynamics. To a much extent, droplet impact affected the heat transfer and fluid flow of the molten pool. With considering droplet impact, the maximum temperature was $2897 \mathrm{~K}$, and the maximum velocity was $1.3 \mathrm{~m} / \mathrm{s}$. There was a strong convection in the molten pool. 
2. The droplet impact made a serious concave deformation and pushed the surrounding liquid upward, which determined the weld reinforcement. With considering droplet impact, the height of the weld was $0.8 \mathrm{~mm}$ bigger than that without considering droplet impact, while the weld width was $0.6 \mathrm{~mm}$ smaller. The droplet impact was the main factor leading to the surface deformation and weld formation.

3. With considering the droplet impact, the Peclet number increased, and the convection in the molten pool was enhanced. With considering droplet impact, the average velocity near the arc center was $0.4 \mathrm{~m} / \mathrm{s}$ higher than that without considering droplet impact. The droplet impact made the convection more stronger, and made the molten pool more homogenous.

4. Droplet impact on the molten pool was fully understood, which was contributed to optimize and precisely control the welding process. The application of the droplet impact on molten pool can provide quantification basis for weld geometry, and it is of great significance in engineering application.

Acknowledgements This work was supported by the National Natural Science Foundation of China under grant numbers 11272316, 11272317, 11672304, and 11502269. In addition, special thanks for the instrument developing project of the Chinese Academy of Sciences (No. yz201636).

\section{References}

1. Yu G, He X.L and Li S.X (2017) Laser manufacturing and its application, National Defense Industry Press, Beijing

2. Ribic B, Palmer TA, DebRoy T (2013) Problems and issues in laser-arc hybrid welding. Int Mater Rev 54(4):223-244. https:// doi.org/10.1179/174328009x411163

3. Rao ZH, Liao SM, Tsai HL (2013) Modelling of hybrid laser-GMA welding: review and challenges. Sci Technol Weld Join 16(4):300 305. https://doi.org/10.1179/1362171811y.0000000022

4. Cho D-W, Cho W-I, Na S-J (2014) Modeling and simulation of arc: laser and hybrid welding process. J Manuf Process 16(1):26-55. https://doi.org/10.1016/j.jmapro.2013.06.012

5. Zhou J, Tsai HL (2008) Modeling of transport phenomena in hybrid laser-MIG keyhole welding. Int J Heat Mass Transf 51(17-18): 4353-4366. https://doi.org/10.1016/j.ijheatmasstransfer.2008.02. 011

6. Gao Z, Wu Y, Huang J (2009) Analysis of weld pool dynamic during stationary laser-MIG hybrid welding. Int J Adv Manuf Technol 44(9-10):870-879. https://doi.org/10.1007/s00170-0081896-4

7. Cho W-I, Na S-J, Cho M-H, Lee J-S (2010) Numerical study of alloying element distribution in $\mathrm{CO} 2$ laser-GMA hybrid welding. Comput Mater Sci 49(4):792-800. https://doi.org/10.1016/j. commatsci.2010.06.025

8. Meng X, Qin G, Su Y, Fu B, Ji Y (2015) Numerical simulation of large spot laser+MIG arc brazing-fusion welding of $\mathrm{Al}$ alloy to galvanized steel. J Mater Process Technol 222:307-314. https:// doi.org/10.1016/j.jmatprotec.2015.03.020

9. Liu S, Siewert TA (1989) Metal transfer in gas metal arc welding: droplet rate. Welding Res Supplement:52-58
10. Ferraresi VA, Figueiredo KM, Hiap T (2003) Metal transfer in the aluminum gas metal arc welding. J Braz Soc Mech Sci Eng (XXV): 229-234

11. Huang Y, Shao Y, Zhang YM (2012) Nonlinear modeling of dynamic metal transfer in laser-enhanced GMAW. Weld J 91:140-148

12. Wang X, Huang Y, Zhang Y (2012) Droplet transfer model for laser-enhanced GMAW. Int J Adv Manuf Technol 64(1-4):207217. https://doi.org/10.1007/s00170-012-4014-6

13. Cai C, Feng J, Li L, Chen Y (2016) Influence of laser on the droplet behavior in short-circuiting, globular, and spray modes of hybrid fiber laser-MIG welding. Opt Laser Technol 83:108-118. https:// doi.org/10.1016/j.optlastec.2016.03.029

14. Patankar SV (1980) Numerical heat transfer and fluid flow. Hemisphere Publishing Corp, New York

15. Bennon WD, Incropera FP (1987) A continnum model for momentum heat and species transport in binary solid liquid-phase change systems-I. Model formulation. Int J Heat Mass Transfer (30):21602170

16. Bennon W.D, Incropera F.P (1987) A continnum model for momentum heat and species transport in binary solid liquid-phase change systems- I I. Application to solidification in a rectangular cavity. Int J Heat Mass Transfer (30):2171-2187

17. Voller VR, Brent AD, Prakash C (1989) The modeling of heat, mass and solute transport in solidification systems. Int J Heat Mass Transf 32:1719-1731

18. He X, Fuerschbach P W, DebRoy T (2003) Heat transfer and fluid flow during laser spot welding of 304 stainless steel. J Phys D: Appl phys (36)1388-1398

19. Ding X, Li H, Yang L, Gao Y (2013) Numerical simulation of metal transfer process in tandem GMAW. Int J Adv Manuf Technol 69(14):107-112. https://doi.org/10.1007/s00170-013-4999-5

20. Rai R, Kelly SM, Martukanitz RP, DebRoy T (2007) A convective heat-transfer model for partial and full penetration keyhole mode laser welding of a structural steel. Metall Mater Trans A 39(1):98112. https://doi.org/10.1007/s11661-007-9400-6

21. Kim JW, Na SJ (1995) A study on the effect of contract tube-toworkpiece distance on weld pool shape in gas metal arc welding. Weld J (74): 141-143

22. He X, Norris JT, Fuerschbach PW, DebRoy T (2006) Liquid metal expulsion during laser spot welding of 304 stainless steel. J Phys D Appl Phys 39(3):525-534. https://doi.org/10.1088/0022-3727/39/ 3/016994

23. Wu CS, Dorn L (1994) Computer simulation of fluid dynamics and heat transfer in full-penetrated TIG weld pools with surface depression. Comput Mater Sci (2):341-345

24. Kim CH, Zhang W, DebRoy T (2003) Modeling of temperature field and solidified surface profile during gas-metal arc fillet welding. J Appl Phys 94(4):2667-2679. https://doi.org/10.1063/1. 1592012

25. Lin ML, Eagar TW (1986) Pressures produced by gas tungsten arcs. Metall Mater Trans B (17B):601-607

26. Kim YS, Eagar TW (1991) Analyses of electrode heat transfer in gas metal arc welding. Weld J (70):20-31

27. Moradi M, Ghoreishi M, Frostevarg J, Kaplan AFH (2013) An investigation on stability of laser hybrid arc welding. Opt Lasers Eng 51(4):481-487. https://doi.org/10.1016/j.optlaseng.2012.10. 016

28. Lin Q, Li X, Simpson SW (2001) Metal transfer measurements in gas metal arc welding. J Phys D Appl Phys 34(3):347-353. https:// doi.org/10.1088/0022-3727/34/3/317

29. Campana G, Fortunato A, Ascari A, Tani G, Tomesani L (2007) The influence of arc transfer mode in hybrid laser-mig welding. J Mater Process Technol 191(1-3):111-113. https://doi.org/10.1016/ j.jmatprotec.2007.03.001G

30. Roepke C, Liu S, Kelly S (2010) Hybrid laser arc welding process evaluation on DH36 and EH36 steel. Weld J (89):140-150 
31. Cao ZN, Dong P (1998) Modeling of GMA weld pools with consideration of droplet impact. J Eng Mater Technol 120(4):313-320. https://doi.org/10.1115/1.2807020

32. Xu GX, Wu CS, Qin GL, Wang XY, Lin SY (2011) Adaptive volumetric heat source models for laser beam and laser + pulsed GMAW hybrid welding processes. Int J Adv Manuf Technol 57(14):245-255. https://doi.org/10.1007/s00170-011-3274-x

33. Faraji AH, Goodarzi M, Seyedein SH, Barbieri G, Maletta C (2014) Numerical modeling of heat transfer and fluid flow in hybrid laserTIG welding of aluminum alloy AA6082. Int J Adv Manuf Technol 77(9-12):2067-2082. https://doi.org/10.1007/s00170-014-6589-6

34. Ribic B, Rai R, DebRoy T (2013) Numerical simulation of heat transfer and fluid flow in GTA/laser hybrid welding. Sci Technol Weld Join 13(8):683-693. https://doi.org/10.1179/ $136217108 \times 356782$

35. Xu P, Bao C, Lu F, Ma.C,He J,Cui H,Yang S (2011) Numerical simulation of laser-tungsten inert arc deep penetration welding between WC-Co cemented carbide and invar alloys. Int J Adv Manuf Technol 53(9-12):1049-1062. https://doi.org/10.1007/s00170010-2898-6

36. Kelmax AK (1978) Heat model for laser welding, J Appl Phys (51): 941-947

37. Peueyo A, Dabezies B, Fabbro R (1994) Thermal coupling inside the keyhole during welding process, laser materials processing: industrial and microelectronics applications. Int Soc Optical Eng 2207:175-184

38. Ducharme R, Kapadia P, Dowden J (1993) A mathematical model of the defocusing of laser light above a workpiece in laser material processing. Proceedings of ICALEO(92):187-197
39. Zhao H, DebRoy T (2003) Macroporosity free aluminum alloy weldments through numerical simulation of keyhole mode laser welding. J Appl Phys 93(12):10089-10096. https://doi.org/10. $1063 / 1.1573732$

40. Haiyan Z, Wenchong N, Bin Z, Yongping L, Masaru K, Takashi I (2011) Modelling of keyhole dynamics and porosity formation considering the adaptive keyhole shape and threephase coupling during deep-penetration laser welding. J Phys D: Appl Phys 44(48): 485302

41. Zhiyong L, Srivatsan TS, Yan LI, Wenzhao Z (2012) Coupling of laser with plasma arc to facilitate hybrid welding of metallic materials: a review. J Mater Eng Perform 22(2):384-395. https://doi.org/ 10.1007/s11665-012-0280-6

42. Le Guen E, Fabbro R, Carin M, Coste F, Le Masson P (2011) Analysis of hybrid Nd:Yag laser-MAG arc welding processes. Opt Laser Technol 43(7):1155-1166. https://doi.org/10.1016/j. optlastec.2011.03.002

43. Zhao H, Debroy T(2001) Weld metal composition change during conduction mode laser welding of aluminum alloy 5182. Metall Mater Trans B (32):163-172

44. Miao H, Yu G, He X, Li S, Chen X (2017) Comparative study of hybrid laser-MIG leading configuration on porosity in aluminum alloy bead-on-plate welding. Int J Adv Manuf Technol 91(5-8): 2681-2688. https://doi.org/10.1007/s00170-016-9917-1

45. Siewert E, Schein J, Forster G (2013) Determination of enthalpy, temperature, surface tension and geometry of the material transfer in PGMAW for the system argon-iron. J Phys D Appl Phys 46(22): 224008. https://doi.org/10.1088/0022-3727/46/22/224008 